thirds the size of one's little finger; there was no visible pulsation in them; veins of arms somewhat distended; no dilatation of veins of chest-walls ; there was some amygdaloid enlargement of glands in inguinal regions, none to be felt in axillæ and neck. On examination of chest there was dulness upon percussion, with markedly increased sense of resistance over manubrium; this extended laterally on the right over a surface included within a line drawn from a point nearly half an inch outside the sterno-clavicular articulation to third cartilage, on the left over an area bounded above by the clavicle, below by the third rib, externally by a curved line from centre of clavicle to third rib. There was an entire absence of all thrill, pulsation, murmur of any kind, or accentuation of the aortic second sound in the dull area; the percussion note was fair everywhere else over front and sides of chest; the lower half of each back was rather hyper-resonant; the resonance in supra-spinous fossæ was equal; there was no interscapular dulness ; inspiration all over the chest was loudly stridulous, expiration being prolonged and here and there accompanied by a sibilant wheeze; the heart's apex was in its normal position; the vertical cardiac dulness was continuous with the dull area above the third rib; there was no increase of the transverse diameter; the heart-sounds were pure and free from murmur; his radial pulses were of equal volume, 120, small, hard, and regular; other systems were normal. He was ordered to take three grains of iodide of potassium every four hours, to inhale hydrocyanic acid vapour, and to paint the area of dulness with equal parts of tincture and liniment of iodine. This gave him considerable relief for a time; his breathing became easier, and he was able to swallow solid food. This amelioration of his symptoms continued up to March 5th, when he lapsed into his former condition.

On March 7th I saw him again with Mr. Biggs. He was in bed. His attitude, appearance, and symptoms were the same as when last seen, excepting that the distension of his jugulars was not so marked, and distinct pulsation occurred in them during the last half of inspiration. His pulse was 144, of the same character as before ; there was no enfeeblement during inspiration. His larynx felt rather tender when handled. There was the same dulness and sense of resistance on percussion over the manubrium; on the left side, this was bounded superiorly by the clavicle, inferiorly by the third rib, and on the outer side by a line from the junction of the inner with the middle third of the clavicle to the third rib. There was no abnormal dulness in any other part of his chest. He got gradually worse. Mr. Biggs on two occasions found that his temperature reached $100^{\circ} \mathrm{Fahr}$. He died on March 20 th.

An examination of the body was made by Mr. Bigg twenty-six hours after death. It was well nourished ; rigor mortis strongly marked; animal heat not altogether gone. On removin $\mathrm{s}$ the sternum, a large, hard, solid mass, of a yellowish-white colour, was found situated in the anterior mediastinum. It measured $3 \frac{1}{2}$ in. vertically, $2 \frac{1}{2}$ in. transversely, and $3 \frac{1}{3}$ in, antero-posteriorly. It was not adherent to the sternum, but was firmly attached on each side to the cartilage of the first rib, especially on the right side; it was also partially adherent to the upper lobe of the left lung; besind, it was easily detached with the finger. Excepting the beart and pericardium, the whole of the structures of the anterior and middle mediastinum were embedded in the growth, the zerves being quite indistinguishable. The large vessels springing from the arch of the aorta were much diminished in calibre. The superior vena cava was completely obliterated, it being impossible to pass even a small probe. The trachea was embraced on two-thirds of its circumference by the growth. The left bronchus was somewhat narrowed. The pericardium contained a small quantity of clear fluid. The heart weighed $8 \frac{1}{2} \mathrm{oz}$; walls thickened; cavities and valves normal. The left pleural carity contained five pints of bloody fluid. The inner margin of the upper lobe of the left lung was infiltrated for two-thirds of an inch with the same growth as in the mediastinum, and scattered throughout this lobe were a few nodules of the same. There was some recent lymph on the lateral middle third of the surface of this lung, and also some on the pleural surface of the chest-wall at a corresponding point. The lower lobe of the left lung was collapsed; there was no apparent emphysema. The right lung was healthy. Liver normal. Other organs not examined. Mr. Field, resident medical officer at the Royal United Hospital, kindly undertook the microscopic examination of the medias- tinal growth. He found it to consist mainly of fibrous tissue, with here and there small strands of lymphomatous tissue.

As to the diagnosis of the patient's condition, any opinion that the dulness in his left infraclavicular region was due to tubercular consolidation was negatived by its extending across the middle line to the right, its non-extension into the acromial angle, the absence of dulness in left supraspinous fossa and scapular region, the apparent integrity of right lung, and, most crucial objection of all, the evidence of pressure upon the large vessels and trachea. The idea of aneurism was rejected on the ground of the patient's age, and there being no history whatever of alcoholism, syphilis, physical strain, or rheumatism, also the markedly increased sense of resistance upon percussion over the dull area, and the total absence in it, or upon its confines, of all pulsation, thrill, vascular murmur of any kind, or accentuation of the aortic second sound. On the other hand, was it a case of mediastinal abscess, similar to a case Dr. Walshe alludes to in his work "On Diseases of the Lungs," where, in conjunction with suppurating cervical glands, a man had all the physical signs of a solid non-aneurismal tumour behind the manubrium, and in which, through a partial liquefaction of a portion of the tubercular mediastinal mass, there was, as in the case of $\mathrm{W} . \mathrm{O}$ towards the end of his life? In W. O_-'s case I imagine this to have been due to the removal through treatment of some associated local consolidation of left lung. Da Costa also mentions, in his "Medical Diagnosis," a case of his own where an abscess of the mediastinum closely simulated an aortic aneurism in the pain, percussion dulness, dyspnos, dysphagia, and altered voice, the only point of distinction being an absence of pulsation. The patient recovered, the abscess breaking internally, and large quantities of pus being expectorated. W. O_'s family history of struma gave some apparent support to such a view of his own case, but there was no history of injury to his chest-walls, neither was there any reason to suppose that his ribs or stermum were diseased; besides, his pain was not so severe as it would probably have been had his case been one of mediastinal abscess ; in addition, there was no hectic, neither, as far as I could make out, did altering his position produce any effect upon the area of dulness. The opinion which I therefore expressed, and in which Mr. Biggs concurred, was, that $\mathrm{W}$. O- was suffering from a tumour in his mediastinum, probably of a malionant nature - a diagnosis which was completely verified by the post-mortem examination.

\section{AN UNUSUAL CASE OF STRANGULATED FEMORAL HERNIA; WITH REMARKS}

BY WILLIAM DUNNETT SPANTON,

SURGEON TO THE NORTH STAFFORDSHTRE INFIRMARY

For the following notes of this case I am indebted to our present house-surgeon, Mr. W. A. Frost.

Charlotte S_- aged thirty-nine, married, having four children, was admitted into the North Staffordshire Infirmary, under the care of Mr. Spanton, on Feb. 17th, 1878, at 12.30 P.M. Had reducible femoral hernia on the right side for three years ; several times had difficulty in reducing it with pain and vomiting. Has worn a truss two years. The hernia descended on the 16 th (the day before admission), between 3 and 4 P.M. She was unable to reduce it. Vomiting occurred in the evening, and several times during the night Taxis was applied by a medical man on the evening of the 16th and morning of the 17th. Bowels relieved last on the morning of the $16 \mathrm{th}$.

On admission, there was a tense swelling, of the size of walnut, immediately below Poupart's ligament; on this she was wearing a truss. Pulse quick, small, and weak; tonctue moist, coated in centre, clean at edges. Considerable abdominal pain, chiefiy in right side and at umbilicus. Ordered thirty minims of tincture of opium ; ice to the hernia. She vomited a small quantity of clear fluid. At 3 P. M. herniotomy was performed by Mr. Spanton. The sac contained half an ounce of bloody clear serum; omentum and small knuckle of intestine congested, but retaining its natural gloss. Tight constriction at crural ring. After division of this, the bowel and omentum were easily returned. Ordered 
half a grain of opium powder every four hours. -9 P.M. Feels comfortable; no pain or vomiting.

Feb. 18th. - Slept fairly well. Menses appeared. Slight pain in lower part of abdomen throughout the day; no tenderness.

19th. - Not much sleep, in consequence of the pains, which came on every quarter of an hour, and lasted two or three minutes. Temperature $102^{\circ}$; pulse 130 , weak. Wound quiet. Slight tenderness in right inguinal region. Abdominal mus cles move freely in deep respiration. -9 P.M. : Pains rather more frequent. Fomentations ordered.

20th.-From 2 till 4 A.M.: Great pain in right inguinal region. Ten leeches applied, which gave great relief.9 A.M. : Temperature $101^{\circ} 4^{\circ}$; pulse 130 ; tongue moist, coated in centre. Abdominal walls moving freely ; soft; no pain. 1 P.M. : Pain returned, but less violent than during the night. An enema of salt and water was followed by two rather free actions of the bowels. Hypodermic injection of morphia ordered instead of pills.

21st.-9 A.M. : Slept well. Slight redness round wound. Lowest suture removed. Slight cough ; pain in coughing, not otherwise.-3 P.M. : Vomited ; repeated several times in course of afternoon and evening; fluid of brown colour, not offensive. To have ice to suck.

22nd.-A bad night; vomited frequently. Eyes sunken. Induration round wound; all sutures removed, giving exit to a few drops of pus. Tongue moist; brownish fur in centre. Patient vomited frequently throughout the day; fluid of a darker colour.

23rd.-Bad night. Tongue moist. Throughout the day she vomited about every five or ten minutes; fluid welled up into mouth with hardly any retching. Free from pain.

24th. - No sleep. Coffee-ground vomiting, with faint freal odour. At 11 A.M. vomiting ceased. In the afternoon the bowels were moved twice, the motions being copious and fluid. At 5 P.M. she became very restless, and at 6.30 died. Necropsy, twenty hours after death. - No union of wound; sac empty. Peritoneum intensely congested throughout. No lymph or stickiness. Small intestine, six inches from ileocæcal valve, adherent for half an inch to abdominal wall, above and to the outer side of the femoral ring. At this point the gut was bent at an acute angle; the portion below was empty and contracted, that above dilated. The adhesion readily gave way, leaving a superficial roughness on the corresponding surfaces. For about three inches in the neighbourhood of the adherent point the intestine was of a darker colour than elsewhere; this faded off gradually above and below. The mucous membrane was of a darker colour than natural throughout, and near the adhesion was of a slate colour, but retained its normal consistence. There was no mark of any constriction on either surface; nothing to indicate what portion of the omentum had been in the sac.

There are several points of interest in this case. The first that strikes one is the fact of a strangulation of a femoral hernia of recent occurrence requiring operation. As we all know, it is in cases of femoral hernia that taxis more often fails; but $I$ am inclined to believe that when this method is had recourse to sufficiently early - before the hernia has become tense and swollen-there is much less difficulty in reducing such hermiæ than is usually stated. For my own part I have seen a considerable number of cases of strangulated femoral herniæ, but almost the only cases in which an operation has been required have been infirmary ones or consultation cases, in which, as a rule, there has been considerable delay.

In this instance the hernia had been down about twentyfour hours when the patient was admitted into the infirmary, and, as taxis had been previously tried by a surgeon who hal seen the patient, I made no further attempt until she was under the influence of ether. Failing then, $I$ at once operated. Now, although it is always desirable, if possible, to avoid opening the sac, in cases of femoral hernia more especially, this seemed to me one of those cases in which it was better, I mean safer, to do so. The hernia was very tense, and the patient had worn a truss upon it up to the time of admission. There was, therefore, a probability that the bowel and the sac would be more or less inflamed or injured, and it was consequently a safer course to see its condition, and act accordingly. As it proved, however, the bowel appeared congested simply ; the surface was perfectly smooth, and the fluid in the sac, although discoloured somewhat, was quite clear, and there were no indications of any existing inflammation, either about the bowel or the sac.
The constriction was tight, and occasioned by the crural ring itself. There were no bands within the sac. The bowel was returned without any difficulty, and a portion of healthylooking omentum, about the size of two fingers, I also returned easily.

After the operation the patient's symptoms were entirely relieved. The sickness, which had been almost incessant, completely disappeared, and the pain ceased. She passed a good night afterwards. The next day she continued comfortable, except a complaint of some pain in the lower abdominal region, which we attributed at the time to the circumstance of her having begun to menstruate-a period at which she habitually suffered much. To this we did not attach much importance, especially as the temperature was only a little over $100^{\circ} \mathrm{F}$. The next day, however, the pain was more about the right inguinal region, though there was still no indication of any general peritonitis, and the temperature rose. As I have already related in the report of the case, the bowels acted freely after an enema, and some relief was obtained by the remedies employed. On the 21sti.e., four days after admission-vomiting returned, and there were indications of renewed obstruction. From this time the symptoms increased in severity, the sickness becoming almost incessant; the bowels, however, acted freely again on the $24 \mathrm{th}$, in the evening of which day she died.

There was found after death far less general mischief than is usual in fatal cases of this kind; but a single patch of inflamed bowel, by which it became adherent to the abdominal wall, and so caused an obstruction almost as complete as that of the hernia itself. This is the peculiar feature of the case, and I cannot find a record of any quite similar one. It seems strange, with such a slender sort of hold, that the bowel should be able to resist, by its angularity merely, the onward force which peristaltic action would produce. And here, I imagine, we come to the explanation of the real difficulty. Although there was no marked indication of such being the case, we may, I think, fairly assume that the point of adherent bowel must have been that portion which, when strangulated, was subjected to the irritating pressure of the truss (which I have already alluded to), and although it bore no sign of injury when seen during the operation, the mischief may have been begun, and produced its fruit afterwards in the patch of lymph by which it glued itself to the abdominal wall. There is an interesting circumstance bearing on this subject which is recorded by Mr. John Wood. In speaking of his cases of radical cure of hernia, he tells us that the single instance in which death resulted from peritonitis was one where the startingpoint of the inflammation was a small adhesion of small intestine, in which at the point of attachment there was evidence of some injury, which Mr. Wood attributed to a truss which had been previously worn. To return, however, to my own case, why should such a slight adhesion have caused obstruction? It can be explained, I believe, only on the supposition that there was, in addition, more or less muscular paralysis of the intestine; for, as we know, a comparatively slight obstruction in the nature of a fold of the bowel, or some other condition, which, under ordinary circumstances, might be overcome, will, when superadded to deficient muscular action, lead to complete stoppage. There is, again, the possibility that the occurrence of the menstrual flow the day after operation may have induced, as it almost certainly would, considerable congestion of the lower abdominal viscera, and so help to bring about the untoward. result.

Now I come to ask whether it would have been possible to have done more for the patient in this case? Would it have been possible to reopen the wound, and release the imprisoned bowel? I do not think it would, even if we could have been sure of the very unusual condition the postmortem examination revealed. And even if it had been set free, would not the process have probably led to more general inflammatory action? To this we can only reply in the affirmative. I carefully considered the justifiability of making any attempt to explore, but as there was no indication to guide us as to the nature of the renewed obstruction-it might have been due to so many different causes-we devoted ourselves to endeavouring to allay inflammatory action, and to sustain the patient, and this is all that $I$ think in such a case could well be done.

There is one other matter to which I will refer, and that is the important lesson-which cannot be too often repeated even when we know it by heart - that the danger in stran. gulated hernia is in almost direct proportion to the delay 
in reduction, and I would add the amount of manipulation or injury; and if we would diminish the present high rate of mortality after operation for hernia, we must endeavour to teach it to others, as well as to act upon it ourselves.

\section{MEDICINE IN BULGARIA.}

By A. IRWIN BOLTON, M.B., A.B., MEDICAL OFFICER, DANUBE AND BLACK SEA RAILWAY, KUSTENDJIE, BULGARIA.

\section{ALBUMINURIA IN AN AGED PATIENT, TREATED BY GALLIC} ACID.

MADAME S-, aged seventy-five, Bulgarian, sent for me on the 23rd March, 1878. She was suffering from dropsy of enormous extent, great difficulty of breathing, insomnia, frequent attacks of vertigo; bowels very irregular, mostly costive. Pulse 90 ; and most peculiarly dicrotous-namely, two beats then a pause, three beats then another pause, and so on regularly repeated. Tongue natural; thermometer under tongue, $96^{\circ}$. Urine scanty, very high-coloured; sp. gr. 1008, highly albuminous and containing blood-corpuscles. Heart-sounds natural, but rhythm corresponding with pulse. The legs were enormously swollen, and the tissues over the right great trochanter very red and painful. Effusion into the abdominal cavity excessive, and, by its presence, causing apnoea. The apex of the heart beat higher than natural, and the region of cardiac dulness was diminished from below upwards, but increased from side to side owing to the upward pressure of the abdominal fluid transmitted through the lung to the heart.

Ordered mercury pill five grains, compound colocynth pill three grains, extract of hyoscyamus two grains, divided into two pills; and after these have operated, gallic acid two drachms, extract of hyoscyamus twelve grains, with sugar of milk, divided into eight powders, one to be taken every three hours. Powder of squills twelve grains, powder of digitalis six grains, mercury pill twenty-four grains, divided into eight pills, one to be taken at bedtime. Diet farinaceous; a little beef-tea and milk, $10 \mathrm{oz}$. per diem. To avoid fluid as far as possible. Hot-water foot bath at night.

March 24th. - Bowels freely opened. Symptoms unchanged. Mcdicines as before.

26th.-Patient much improved. Breathing less difficult. Heart's action improved. Urine copious, clearer, and albumen less; blood-corpuscles undiscernible. Insomnia less. Continue treatment, but increase the gallic acid to twenty grains in each powder. The night pill and diet as before.

27 th. - Patient improving very rapidly. Urine as yesterday, but more copious. Bowels confined. Edema greatly diminished. Ordered compound rhubarb draught and omit gallic acid until the bowels are relieved. Tenderness of trochanter is increasing. Ordered for this a lotion consisting of sulphuric acid one drachm and a half, linseed oil two drachms, balsam of Peru one drachm.

28th.-Bowels freely moved; patient bright and cheerful ; dropsical effusion everywhere rapidly diminishing; urine very copious and clear, contains not a trace of albumen, sp. gr. 1015 ; pulse natural ; heart's apex beats in its natural position; breathing normal ; sleeps well. Ordered to continue the powders every four hours, pill at bedtime as usual; the pediluvium as before; farinaceous diet.

29th.--Only slight œdema of legs remaining; patient improving. Remedies continued.

3lst.-Improving; bowels confined. Ordered compound rhubarb draught.

April 4th.--After this date I omitted professional visit, as my patient was convalescent.

I omitted to mention that this patient had been under the treatment of a native practitioner for six weeks previous to my attendance, and during that time was treated by means of friction, with ointment and oil to the limbs. She stated that her attack commenced after getting a severe wetting.

I.TONTINEXCE OF URINE, THE RESULT OF INJURY TO THE BLADDER FRON LTTHOTOMY, TREATED BY ERGOT.

Mir. G-, aged thirty-one, an Armenian, of fairly robust frame, but very sallow complexion, came under my notice on Angust 1st, 1878, suffering from incontinence of urine of eight years' standing. His person emitted a filthy stench, and his trousers were deeply stained by the urine constantly trickling from him. He wears a large soft cloth in the fork of his trousers to catch the urine as it comes from him. The patient was born in Armenia, and there, from the age of five years, he was known to have stone in the bladder. There being no surgeon in his village capable of operating upon him, he had to remain a wretched sufferer until he arrived at the age of twenty-three, when, having put together a little money, he started for Constantinople. Here he went under the care of a Turkish naval surgeon (Dr. Gustantine), who cut him, using the median operation, and removed astone weighing forty-two drachms. The wound soon healed, and he had no difficulty about micturition, until three months after the operation, when, whilst making water, the stream suddenly stopped, and he was attacked with great pain. The same surgeon attended, and introduced a sound. On its withdrawal the urine passed freely. The surgeon said there was another small stone, and the day following he again operated, removing a second stone weighing twelve drachms. The wound from this operation also healed quickly, but from this period (now eight years) he never has been able to retain his urine when walking or working. Previous to the removal of the first stone he says his sufferings at times were almost unbearable.

Looking upon this man's case as one of relaxation (if I may so call it) of the muscular tissue of the neck of the bladder (the result of the lithotomy sound), especially the sphincter vesicæ, accompanied with unhealthy state of the mucous membrane, I resolved to remedy the latter first, and then try the effects of ergotine internally. Before relating further I may mention that I was led to adopt the ergotine treatment owing to the accounts I have read of its marvellous effects upon involuntary muscular fibre. To correct the unhealthy mucous lining of the bladder I treated him with benzoic acid and buchu internally; compound belladonna ointment applied by friction over the pubes and perineum; enjoined rest in the recumbent position ; mucilaginous diet and scanty fluid; cold sea-water douche twice daily. After four days of this treatment, seeing that he complained of no bladder uneasiness, and only suffered from the incontinence, I ordered him the following: Gallic acid, twelve grains; extract of ergot (Bonjean's), half a drachm; extract of nux vomica, two grains, divided into twelve pills, one to be taken every three hours in the day. The douche to be continued, and the diet and rest as before.

On the fourth day of this treatment the patient observed that his urine only occasionally came away, and then only when making some straining or bending motion of his body. He was so pleased that he begged of me to make the pills stronger. I did so, adding a quarter grain to each pill. $\mathrm{He}$ continued taking these pills, one every three hours, until the seventh day of the ergot treatment. At this period he had full control of his bladder, so far as the constant trickling was concerned; but when the desire for voiding his urine came on, he was obliged at once to obey the call or pay the penalty of having his trousers wet through. On the eighth day of the ergot treatment I reduced the number of pills daily to one three times a day. This number he continued taking daily for a week longer, when he said he was perfectly well, and left me much gratified.

Whether I calculated rightly what the effect of the ergot in this case would be, I will leave it for my readers to judge.

In conclusion, I may remark that I have had valuable assistance from ergot in many diseases prevalent here: in dysentery especially; in hæmorrhage from the bowels; in typhoid, frequently. In uterine hæmorrhage (severe) I employed it in one case hypodermically, as lately recommended in THE LANCET, with complete success. In hæmoptysis I find it most beneficial, and am now employing it in a severe case of phthisical hæmoptysis with marked benefit.

Midland Medical Society.-The annual meeting was held in Queen's College on the 16th inst., when the following officers were elected :-Mr. Herbert M. Morgan, President; Mr. Harmar, Hon. Treasurer; Dr. Thomas Savage and Mr. John Garner, Hon. Secretaries. The names of Mr. Gamgee, Dr. Sawver (late President), Mr. William Thomas (late hon. sec.), Mr. West, and Dr. Welch, were added to the Council. Professor Lister, F.R.S., has consented to deliver the inaugural address on Wednesday, the 30th inst. 